\title{
Addressing non-communicable diseases in the Western Cape, South Africa
}

\author{
Nasheetah Solomons, ${ }^{1}$ H. Salome Kruger, ${ }^{2}$ Thandi R. Pouane ${ }^{3}$ \\ ${ }^{1}$ Department of Dietetics and Nutrition, Faculty of Community of Health Sciences, University of the \\ Western Cape, Cape Town; ${ }^{2}$ Centre of Excellence for Nutrition, Faculty of Health Sciences, North-West \\ University, Potchefstroom; ${ }^{3}$ School of Public Health, Faculty of Community of Health Sciences, University \\ of the Western Cape, Cape Town, South Africa
}

\begin{abstract}
Significance for public health
Chronic non-communicable disease (CNCD) epidemic should be addressed as a matter of urgency. Many organisations in the private and public sectors have responded by developing and implementing CNCD intervention programmes. Despite this, the number of persons being diagnosed with a CNCD continues to rise annually. This raises the question why existing CNCD nutrition-related messages currently being disseminated to address the CNCD epidemic are not achieving the desired effect. It could be that current health messages are not reaching the target groups; the health messages are being misunderstood, or the health messages are not addressing the target populations' needs. Gaps in addressing the CNCD epidemic can be identified when needs of a target population are identified. These needs should be compared with what Department of Health officials consider to be the best nutrition-related strategies to address the epidemic. This could be the first step in attempting to identify where current strategies can be adjusted to meet the target population's needs.
\end{abstract}

\section{Abstract}

Background: Chronic non-communicable diseases (CNCDs) are increasing with grave consequences to countries' development. The purpose of this study was three-fold: (1) to determine challenges PURE study participants faced regarding CNCD interventions and what they required from a CNCD intervention programme, and (2) to explore courses of action Department of Health (DoH) officials thought would perform best, as well as (3) to determine what DoH officials perceive to be obstacles in addressing the CNCD epidemic.

Design and methods: A subsample of 300 participants from the Prospective Urban and Rural Epidemiological study's Western Cape urban cohort and six key officers from the DoH were recruited to participate in this cross-sectional study. Questionnaires were used in face-to-face interviews with the PURE study participants and DoH officials, together with the multi-criteria mapper (MCM) interviewing method with the latter.

Results: Most PURE participants were overweight/obese, but not keen to participate in weight loss interventions. They sought education on foods associated with weight gain, shopping lists, cooking lessons and recipes from CNCD intervention programmes. Department of Health officials regarded the integration of health services, community participation, amongst others as the most favourable options to address the CNCD epidemic.

Conclusions: The integration of health services, community participation, food taxation and improving inter-sectoral partnerships were viewed as the most feasible options to address the CNCD epidemic according to the DoH officials. At community level, the needs for education and practical hints were expressed. Current CNCD interventions should be adapted to include the context-based needs of communities.

\section{Introduction}

Chronic non-communicable diseases (CNCDs) which include cardiovascular disease, diabetes, certain cancers and chronic lung disease were responsible for more than two thirds of global deaths in $2010 .{ }^{1}$ According to Statistics South Africa, diseases of the circulatory system were the most common underlying cause of death at $18.5 \%$ of all deaths in South Africa,${ }^{2}$ whilst in the Western Cape Province $17-25 \%$ of the disease burden can be accounted to CNCDs. ${ }^{3}$ It has been estimated that approximately 950000 people have hypertension and 330,000 person have been diagnosed with diabetes in the Western Cape Province. In addition, the number of deaths due to diabetes has been found to be higher in the Western Cape compared to those in other provinces of South Africa. ${ }^{2}$

Modifiable risk factors for CNCDs include excessive alcohol use, long-term use of tobacco products, physical inactivity, consumption of foods high in sugar, salt, fat and a low in fibre, fruit and vegetable intake. ${ }^{3}$

The South African National Department of Health (DoH) developed its Strategic Plan for the Prevention and Control of Non-Communicable Diseases 2013-17 based on targets set at the South African Summit on the Prevention and Control of Noncommunicable diseases held in September 2011. This document serves as a commitment to address to CNCDs epidemic in South Africa. ${ }^{4}$ On 30 March 2015, the DoH launched its Western Cape on Wellness (WoW!) initiative which is enabled through a transversal Working Group comprised of the University of Cape Town, University of the Western Cape, Stellenbosch University, Biokinetics Association of South Africa (BASA), 44ten MEDIA, the Heart and Stroke Foundation of South Africa (HSFSA), Pharma Dynamics, SiyaGyma-Sa, Discovery Health and Eskom with Virgin Active and Ubuntu Trust as additional sponsors. This initiative aims to promote a culture of wellness at and across the workplace, community and school levels by means of health-related physical activities and healthy eating. ${ }^{2}$

It has been stated that not only can mortality in South Africa be decreased by $20 \%$ by addressing harmful alcohol use, tobacco use, salt intake, high blood pressure, increased blood glucose and diabetes, and obesity, but an added benefit would be a decrease in early disability. ${ }^{5}$ Strategies which have been implemented in an attempt to address CNCDs in South Africa include the Tobacco Products Control Act of 1993 which bans advertising and protects non-smokers from exposure to cigarette smoke and the Liquor Act 
(Act 59 of 2003) which bans advertising of alcoholic products to children and restricts trading hours. In addition "sin tax", i.e. tax on tobacco and alcoholic products is increased annually. ${ }^{6}$ The reduction of industrial trans-fat content of all oils or fats in foods to a maximum of 2 per cent of total calories which was legislated in 2011 and the step-wise reduction of the salt content of a range of highly salted foods was legislated in 2013 with the first phase of salt reduction coming into effective on the $30^{\text {th }}$ of June $2016 .{ }^{7}$ In 2019, the South African Finance minister proposed an increase on the sugar tax on sugar-sweetened beverages which the state implemented on 1 April 2017. ${ }^{8}$

Taking the burden of CNCDs and regional, as well as national prevention initiatives into account, the research questions were the following: (1) What are the challenges and expectations of adults in the Western Cape regarding CNCD interventions? (2) What courses of action would perform best to prevent CNCDs according to relevant DoH officials? (3) Are DoH officials aware of existing CNCD policies and what factors do they perceive to be obstacles in addressing the CNCD epidemic? The purpose of this study was three-fold: (1) to determine challenges the PURE study participants faced regarding $\mathrm{CNCD}$ interventions and what they required from a CNCD intervention programme, (2) to explore what courses of action DoH officials involved in the prevention of the CNCDs epidemic thought would perform best, as well as to (3) determine officials' awareness of existing CNCD policies and what factors they perceive to be obstacles in addressing the CNCD epidemic.

\section{Materials and Methods}

\section{Research design}

This study made use of a cross-sectional design and data collection took place during July 2014 to July 2016.

\section{Sampling and setting}

The Prospective Urban and Rural Epidemiological (PURE) study aimed to recruit approximately 150,000 participants aged between 35 and 70 years living in more than 600 communities in 17 low-, middle-, and high-income countries around the world. The participating countries' selection were based on representativeness of different economic levels and the study sites included are based on commitment of investigators to collecting good quality data over the planned 10 -year period. ${ }^{9}$ The University of the Western Cape's (UWC) School of Public Health (SoPH) committed itself to carry out data collection in Langa (urban community) in the Western Cape Province and Mount Frere (rural community) in the Eastern Cape Province. The sample size of the University of the Western Cape's PURE urban study site consisted of 1000 males and females. For the purpose of this study a subsample of 300 participants as determined by sample size of similar studies ${ }^{10}$ was randomly selected from the three areas (old Langa, the Zones and the Hostels) in the Western Cape urban cohort in Langa to complete the Challenges to Intervention Programmes questionnaire. Lists compiled at baseline data collection containing the PURE study participants' contact details were used to randomly select 100 participants from each of the three areas in Langa. Baseline demographic and anthropometric (height, weight, waist and hip circumferences) data and information on diagnosed CNCDs (diabetes, hypertension and cancer) obtained for these participants in 2010 were used.

Ten key officials (five CNCD intervention programme man- agers and five CNCD intervention programme implementers) from the DoH who are involved in the prevention and treatment of CNCDs were invited to participate in the study by means purposive referral sampling. These DoH officials were contacted by means of electronic mail in order to set up an initial meeting. During this meeting the purpose of the study was explained, and information about the multicriteria mapper (MCM) interviewing method (by means of a demonstration) was provided. ${ }^{11}$ In addition, anonymity was discussed, informed consent was obtained, and a date was then set for the actual interview with those who agreed to participate in the study. In the end six (three managers and three implementers) of the ten DoH officials identified agreed to participate in the study. The managers group consisted of a Director of Nutrition, a Health Promotion manager, and a Wellness Programme manager. The implementers group consisted of a Family physician, a Dietitian, and a Community-based health programme worker.

\section{Assessment instruments and multi-criteria mapping}

Two questionnaires consisting of open-and-closed-ended questions were developed. The first questionnaire (Challenges to CNCD intervention programs) was used to assess challenges PURE study participants faced with regard to intervention programmes. This questionnaire also assessed PURE study participants' satisfaction with current CNCD intervention programmes, their willingness to join an intervention programme, reasons for not wanting to join CNCD intervention programmes, and what they desired from a CNCD intervention programme. ${ }^{12}$ The second questionnaire was used to assess DoH officials' awareness of existing CNCD policies and what factors they perceive to be obstacles to addressing the $\mathrm{CNCD}$ epidemic.

The Multicriteria mapping (MCM) interviewing method, ${ }^{11}$ a decision analysis tool was used to collect data during face-to-face interviews with DoH officials, which were audiotaped. This method makes use of a four-step approach: (1) DoH officials chose the options they wanted to assess from the list disseminated during the initial meeting, (2) Criteria were defined by each DoH official to assess the chosen options, (3) DoH officials assigned a score to each option against their defined criteria, and (4) lastly, they assigned a weight to each criterion according to importance. ${ }^{13}$ These results were then transformed into bar graphs by the MCM programme software.

Prior to the initial meeting with the DoH officials, a list of courses of action that could be employed to address CNCDs as identified from literature, was drawn up. ${ }^{13-24}$ These were then grouped into core options which are criteria all DoH officials were required to assess during the interview, and discretionary options from which DoH officials could select three or more criteria if they felt the core options did not address all the criteria they deemed necessary to address the CNCD epidemic in South Africa. At the start of the interview the DoH officials were allowed to add to the list of core options if they felt that not all possible options were provided. This added option was then assessed together with all the other core options from the original list developed by the researcher.

\section{Data collection}

One trained fieldworker conducted face-to-face interviews with the 300 PURE participants and completed the challenges to intervention questionnaire during the period 10 July 2015 to 25 November 2015. Demographic and anthropometric data were obtained by means of the standardised PURE adult questionnaire, $, 925,26$ during face-to face interviews by trained fieldworkers who also took participants' physical measurements (weight, 
height, waist and hip circumference). Weight was measured with the subject wearing minimal clothing (and after subjects were asked to empty out their pockets) to the nearest $0.1 \mathrm{~kg}$, using a digital scale (UC 321 Precision scale). Height was measured using a stadiometer (Detecto 3PHTROD) with the participant standing with normal posture and barefoot. Measurements were read after ensuring subject's head was in the Frankfort plane and to the nearest $0.1 \mathrm{~cm}$. Body mass index (BMI) was calculated by dividing the weight $(\mathrm{kg})$ by the height $(\mathrm{m})$ squared and presented by BMI category. Waist circumference was measured over minimal clothing at the narrowest part between the rib cage and iliac crest using a nonstretchable measuring tape (Dean). Hip circumference was measured over minimal clothing at the widest part of the body over the buttocks, with the same measuring tape (Dean). Two readings were taken and recorded to the nearest $0.1 \mathrm{~cm}$ and the mean calculated. Waist-hip ratio (WHR) was calculated by taking the waist (cm) and dividing it by the hip circumference $(\mathrm{cm})$. Waist to height ratio (WtHR) was calculated by dividing the waist measurement $(\mathrm{cm})$ by the height $(\mathrm{cm})$. Data of previously diagnosed CNCDs (hypertension, diabetes and cancer) were also collected at this time by means of the adult questionnaire.

The researcher used the MCM interviewing method as a decision analysis too ${ }^{11}$ to collect data during face-to-face interviews from DoH officials. Interviews took place over the period of 10 December 2015 to 1 July 2016. Interviews lasted between one and a half to two hours.

\section{Ethics approval}

Ethics approval for the Western Cape PURE study was obtained from the Research and Higher Degrees committee from the University of the Western Cape (project number 13/3/5) as well as for the additional interviews with the study participants and DoH officials. Written informed consent was obtained from each participant and confidentiality and anonymity was maintained by using participant numbers and no names on all study material.

\section{Data analysis}

The response rate for the completion of the challenges to inter- vention programs questionnaire by the PURE study participants was $100 \%(\mathrm{~N}=300)$, and for the DoH officials it was $60 \%(\mathrm{~N}=6)$. Anthropometric and socio-demographic data, collected in 2010, was however only available for 235 of the 300 selected PURE study participants $(78.3 \%)$. Most data deviated from the normal distribution. Therefore, medians and interquartile range were calculated for continuous demographic and anthropometric data of the women. Percentages and frequencies were calculated for categorical demographic and anthropometric data. The presence of associations between willingness to join an intervention programme and BMI category (overweight/obese $\left[\mathrm{BMI} \geq 25 \mathrm{~kg} / \mathrm{m}^{2}\right]$ vs underweight $/$ normal weight $\left[\mathrm{BMI} \leq 24.9 \mathrm{~kg} / \mathrm{m}^{2}\right]$ ), was determined by means of the chi square test. Data analysis was done using Statistical Package for Social studies (SPSS) version 23 (SPSS Inc., Chicago, IL, USA) software programme. The data obtained by means of the MCM interviewing method was prepared for analysis as described in the MCM manual Version 1.2. ${ }^{27}$ For analysis, the predefined options were grouped into clusters (Table 1) and criteria identified by the DoH officials were categorised into groups termed "issues" in MCM. Five sets of issues were identified and used to analyse the assessment of the performance of the predefined options. The DoH officials were categorised according to two perspectives, i.e. management and implementers. Quantitative data is represented by means of bar charts generated by $\mathrm{MC}$ Mapper. Qualitative data was obtained from the transcripts of each interview and organised according to themes together with the textual data entered into MC Mapper during the interviews which provided information on the reasons for the scores given. The data was then analysed using the MCM analysis 2016 (University of Sussex) software.

\section{Results}

The majority of the PURE study participants comprised of women $(74.5 \%)$. Sixty percent $(n=141)$ of the PURE participants had a high school education and the majority $(75.7 \% ; n=178)$ were unemployed. Hypertension (21.7\%) and type 2 diabetes $(13.2 \%)$

Table 1. Intervention options to address CNCDs according to issues and criteria identified by DoH officials during the MCM interviews.

\begin{tabular}{|c|c|c|c|}
\hline \multirow[t]{2}{*}{ Issue group } & \multirow[t]{2}{*}{ Criteria } & \multicolumn{2}{|c|}{ Predefined options to address CNCDs } \\
\hline & & Core options & Discretionary options \\
\hline Resources & $\begin{array}{l}\text { Human resources, funding, } \\
\text { money, equipment, tools, } \\
\text { internet, checklists }\end{array}$ & $\begin{array}{l}\text { Healthy food subsidies; Cheaper prices } \\
\text { of healthy foods }\end{array}$ & $\begin{array}{l}\text { Improve training of health professionals in CNCD; } \\
\text { Integrated health service delivery; } \\
\text { Skill-shifting among health professionals; } \\
\text { Improve the school curriculum by including more } \\
\text { health and nutrition education; Compulsory free } \\
\text { annual medical check-up; Increased use of sugar and } \\
\text { fat substitutes; Growing healthier foods such } \\
\text { genetically-modified (GM) foods }\end{array}$ \\
\hline Collaboration & $\begin{array}{l}\text { Relationships, community } \\
\text { participation, community-based } \\
\text { participation, capacitation }\end{array}$ & $\begin{array}{l}\text { Community participation; } \\
\text { Improving inter-sectoral partnerships }\end{array}$ & Healthier restaurant menus \\
\hline $\begin{array}{l}\text { Awareness } \\
\text { creation }\end{array}$ & Health promotion, knowledge & & $\begin{array}{l}\text { Improved health education of citizens; } \\
\text { Improve health information systems }\end{array}$ \\
\hline Accountability & $\begin{array}{l}\text { Policy and legislation, } \\
\text { information, monitoring } \\
\text { and governance }\end{array}$ & $\begin{array}{l}\text { Control of food and drink advertisements; } \\
\text { Legislation and regulation for CNCD (policies); } \\
\text { Fatty and sugar-sweetened food tax }\end{array}$ & $\begin{array}{l}\text { Nutrient analysis of catering } \\
\text { menus to show energy, } \\
\text { sugar, salt and fat content }\end{array}$ \\
\hline Commitment & $\begin{array}{l}\text { Policy and legislation, } \\
\text { mental commitment }\end{array}$ & $\begin{array}{l}\text { Control of food sales at public institutions and places; } \\
\text { Compulsory food labelling }\end{array}$ & $\begin{array}{l}\text { Improve workplace health initiatives; } \\
\text { Control marketing terminology on food labels } \\
\text { (e.g. use of "lite") }\end{array}$ \\
\hline
\end{tabular}


were the CNCDs most commonly reported by the PURE study participants. The anthropometric and socio-demographic data of the subsample of 235 of the 300 selected PURE study participants did not differ significantly from the data of the participants excluded from the total sample as presented in Table 2. Responses to the challenges to intervention questionnaire are also shown in Table 3. The majority $(71.1 \%)$ of the PURE study participants were classified as overweight/obese (BMI $\geq 25 \mathrm{~kg} / \mathrm{m}^{2}$ ). Most of the participants $(n=229)$ however, indicated that they were happy with their current weight and only $24 \%$ of the participants expressed a desire to lose weight. Concern for their health and their clothes being too tight were the reasons provided for wanting to lose weight. Furthermore $41.7 \%$ of participants expressed willingness to attend weight loss programmes. There was, however, a significant association between BMI category and willingness to join a weight loss programme $(\mathrm{P} \leq 0.0001)$, with overweight/obese participants less likely to join a weight loss programme.
Responses to the challenges to intervention questionnaire also included that PURE participants expected to gain education on what foodstuffs to purchase, reasons for weight gain and recipes for healthy dishes from CNCD interventions. Other needs identified by participants included exercise classes, how to cook healthier versions of their traditional dishes and information in their home language. Challenges participants experienced with implementation of, and adherence with CNCD interventions include access to facilities, cost and availability of foodstuffs recommended, family responsibilities and peer pressure (Table 3). From the data obtained by means of the MCM interviewing method the predefined options to address CNCDs were grouped into issues and criteria identified by DoH officials (Table 4). Five main issues and criteria for each were identified and performance of the predefined intervention options were analysed according to these issues. As depicted in Figures 1 and 2 all DoH officials (both managers and implementers) identified community participation and improving

Table 2. Variables collected from PURE study participants and data sources for this study. PURE study participants (n=235); data collected in 2010, median (interquartile range).

\begin{tabular}{llll} 
Variable & Sulbsample for $2015(\mathrm{n=235})$ & Excluded from total sample $(\mathrm{n=449})$ & P \\
Age (years) & $51.2(40,57)$ & $51.0(42,57)$ & 0.81 \\
Body weight $(\mathrm{kg})$ & $78(64.5,97)$ & $80(65.2,97.5)$ & 0.72 \\
\hline Height $(\mathrm{cm})$ & $161(155,167)$ & $159.0(154,165)$ & 0.35 \\
Body mass index $(\mathrm{kg} / \mathrm{m} 2)$ & $30.3(24,38.6)$ & $31.7(25.3,40.2)$ & 0.21 \\
\hline Waist circumference $(\mathrm{cm})$ & $97.7(83.5,109.1)$ & $97.0(85.2,109.0)$ & 0.43 \\
Systolic blood pressure $(\mathrm{mm} \mathrm{Hg})$ & $134(119,151)$ & $137(120,152)$ & 0.12 \\
\hline Diastolic blood pressure $(\mathrm{mm} \mathrm{Hg})$ & $87(79,97)$ & $87(78,96)$ & 0.17 \\
Employment $(\%)$ & $44(18.7)$ & $89(19.8))$ & 0.23 \\
\hline
\end{tabular}

Table 3. Challenges with implementation and adherence to CNCD interventions. Data collected in 2015 using questionnaires ( $\mathrm{n}=300$ ).

\begin{tabular}{lll}
\hline Challenge & Number of respondents & $\%$ \\
Lack of money to purchase foods recommended & 255 & 85 \\
Not liking the taste of recommended foods & 216 & 72 \\
\hline Lack of availability of foods recommended by health workers in the community & 155 & 52 \\
Access to facilities where interventions are offered & 189 & 63 \\
\hline Peer pressure to behaviour change & 135 & 45 \\
Family responsibilities competing with adherence & 220 & 73 \\
\hline The perception that it is hard to quit smoking (smoker) & 42 & 72
\end{tabular}
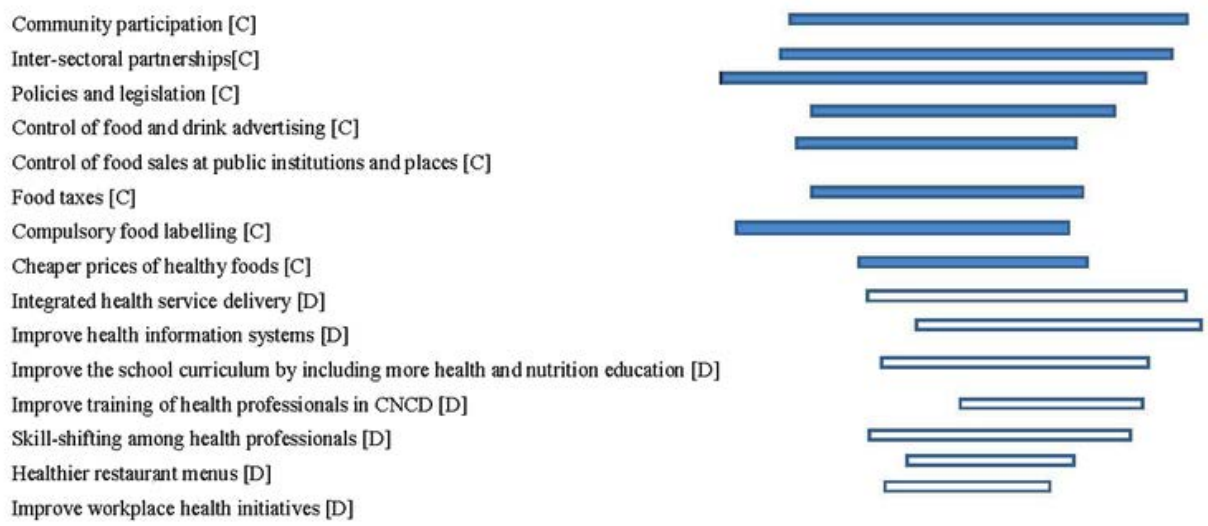

$\begin{array}{lllllllllll}0 & 10 & 20 & 30 & 40 & 50 & 60 & 70 & 80 & 90 & 100\end{array}$

Figure 1. Range of ranks of issues identified and assessed by managers (DoH officials) during MCM interviews ( $n=3)$. 
inter-sectoral relationships and collaboration, as the two most important core options. Community involvement especially, was considered very important for all DoH officials. Two DoH officials (the Dietitian and the Wellness Programme manager) in particular, felt very strongly that interventions will not be successful unless the community was empowered and involved in all processes from start to finish. The following quotes demonstrate the opinion of the Wellness Programme manager: "They must be involved from the outset and all stages and they must be active partners in the process" and "They must also ultimately direct what needs to be done." A quote from the Dietitian confirms this view: "Programmes will fail if just imposed." Policy and legislation were also regarded as important by both implementers and managers (DoH officials) since this was viewed as the control and accountability, but their effectiveness was viewed as being dependent on the availability of human resources and budgetary constraints. These views are demonstrated by the following quotes from managers: "Legislation might be there but it is not implemented or monitored" (Wellness Programme manager). "There is nobody to write, implement and police the policies" (Health promotion manager). Implementers had the same views expressed by the following quotes: "No money is allocated to prioritise to get HR, equipment and put policies in place (Family Physician). "We need skilled people to write legislation and to regulate that laws are properly implemented" (Community-based Health programme worker).

Food supply and control of food sales, and advertisements were seen as less favourable options, since DoH officials considered their efficacy to be reliant on the organisations' policies and industry. Their views were expressed by the following quotes from the Community-based Health programme worker: "Cannot control without extensive human resources" and the Family Physician: "People are prepared to break laws." Although food taxes on high salt, sugar-sweetened, and fatty foods were reported to be feasible options, it was felt that home industries and cheaper food items being imported will not be monitored effectively due to human, laboratories and monetary constraints. The efficacy of cheaper prices of healthy foods and healthy food subsidies were also not considered feasible options. The dietitian and Nutrition director were both of the opinion that this option will not have a great impact as expressed by the following quotes: "Those who have money will still buy what they want to" (Dietitian) and "People will buy what they want and can afford" (Nutrition director).

Improving health information systems and the integration of health service delivery were ranked very highly by all DoH officials, even though health service integration was considered to be a formidable task. The following opinion was expressed by the dietitian: "Integration of health services involves changing an existing system, which will be difficult." Improving the school curriculum was the one option implementers also regarded as important, however this was heavily dependent on the Department of Education and not within the scope of practice of DoH officials. The use of genetically-modified food, sugar and fat substitutes did not find favour with any of the DoH officials.

The obstacles to address the CNCD epidemic at government and community level identified by DoH officials during interviews are listed in Table 4. The obstacles mirror the issues associated with intervention options, including lack of inter-sectoral collaboration, lack of community participation and lack of policies to control access to unhealthy foods.

\section{Discussion}

The most important results of this study were that the PURE participants required education on foods associated with weight gain, what foods and drinks to purchase, how to prepare food and recipes from a CNCD intervention programme, while Department of Health officials stated that integration of health services, community participation, improving inter-sectoral partnerships and food taxation would perform best to prevent the CNCD epidemic.

Even though the majority of the PURE participants were classified as overweight/obese less than $25 \%$ expressed a desire to lose weight and less than half were willing to participate in weight loss programmes. This could be due to cultural influences since Black women associate being overweight with social standing, health and beauty. ${ }^{28,29}$ Another possible reason could be a lack of knowledge regarding the risk for $\mathrm{CNCD}$ associated with obesity. This could be

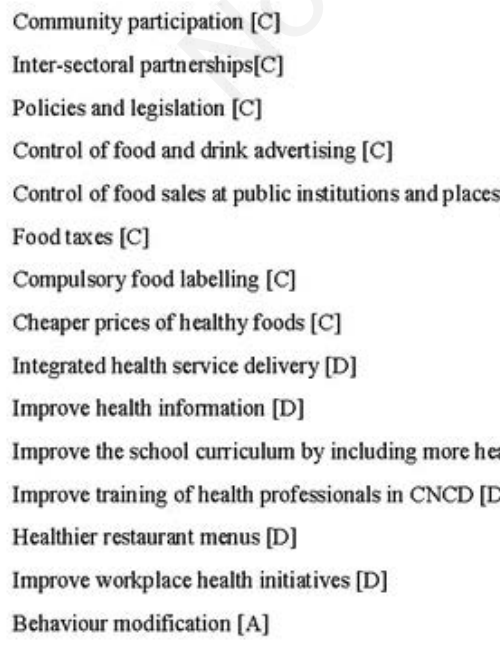

Community participation [C]

Inter-sectoral partnerships $[\mathrm{C}]$

Policies and legislation $[\mathrm{C}]$

Control of food and drink advertising [C]

Control of food sales at public institutions and places [C]

Food taxes [C]

Compulsory food labelling [C]

Cheaper prices of healthy foods [C]

Integrated health service delivery [D]

Improve health information [D]

Improve the school curriculum by including more health and nutrition education [D]

Improve training of health professionals in $\mathrm{CNCD}$ [D]

Healthier restaurant menus [D]

Behaviour modification [A]

Figure 2. Range of ranks of issues identified and assessed by implementers (DoH officials) during MCM interviews (n=3). 
inferred from the expectations of PURE participants from CNCD intervention programmes, such as education on what causes weight gain and how to prepare healthy food. Overweight and obesity are known risk factors for the development of CNCD. ${ }^{30}$ Increases in overweight and obesity in low- and middle-income countries are now on par with those seen in high-income countries. This is as a result of globalisation and urbanisation which result in changes in lifestyle and food consumption. ${ }^{31}$ More than half (60.7\%) of the participants were unemployed. It has been previously reported that adherence to health messages and dietary guidelines is often poorer in persons of lower socio-economic status. Additionally, cultural influences, costs, food availability and personal taste affects acceptability of foodstuffs recommended for a healthy lifestyle. ${ }^{32}$ The majority of the PURE participants interviewed expressed a need for education (cooking lessons, what foodstuffs to purchase). This could indicate that even though there are publicly available health information, it does not reach everyone, or that the messages are not properly understood. It is known that health and nutrition education are crucial components of any health intervention. ${ }^{33}$ Policy and legislation were considered by DoH officials to be very important to address the CNCD epidemic. Some best buy interventions suggested by the literature to address the CNCD epidemic are to reduce tobacco and alcohol use, reducing the trans-fat and salt content of foodstuffs, banning advertisements of unhealthy foods to children, and the promotion of physical activity. ${ }^{34}$ South Africa has responded by setting out specific targets in its strategic plan for the prevention and control of non-communicable diseases 2013-2017 and the implementation of Tobacco Products Controls Act of 1993, the Regulations Relating to Trans fats in Foodstuffs No. R.249 (2010); amendment to Foodstuffs, Cosmetics and Disinfectants (54/1972): Regulations relating to the reduction of sodium in certain foodstuffs and related matters No.3 35509 R. $533 .{ }^{35}$ Regarding the control of the food supply cluster (regulation of food sales at schools, food taxes, cheaper prices of healthy foods, food subsidies and healthier restaurant menus), food taxes received the most optimistic response. Taxes on alcoholic beverages and tobacco products have been in existence since 2002 and since the early 1990s, respectively. ${ }^{36}$ In July 2016 the South African National Treasury released a policy paper taxation of sugar sweetened released in July 2016 for comment with the view to implement this in 2017. ${ }^{37}$ Evidence to support a reduction in the consumption sugar sweetened foods as a result of sugar tax exist. In Mexico for example, sugar tax resulted in a change in purchasing behaviour with a reduction in the purchasing of sugar taxed food items seen across all socio-economic levels. ${ }^{38}$
The majority of the DoH officials regarded food labelling (food information cluster) to be important. They, however, agreed that the current labelling used is not user-friendly, especially to those who are illiterate. The South African government passed an amendment to the Foodstuffs, Cosmetics and Disinfectants Act relating to the labelling and advertising of foodstuffs No. R.429.39 A recent review supports the opinion of the DoH officials that food labels are complex and do not always have the desired effect. ${ }^{40}$

The integration of health services was also considered favourable by the DoH officials even though it was acknowledged that it would be a momentous task. A recent study investigating the integration of NCD, HIV/AIDS and mental health care by empowering chronically ill patients to take care of their own health, found that this option would be beneficial in improving the quality of health service delivery. ${ }^{41}$ Community participation was viewed overall by DoH officials as the best option to tackle the CNCD epidemic. The North Karelia project in Finland is a good example of a project where community participation has proven to be successful. ${ }^{42}$ Despite the general view that industry is money driven, strengthening inter-sectoral partnerships was seen as a favourable option. As part of their social responsibility many of the big retailers have implemented some form of health intervention programme. The big South African supermarkets such as Pick'n'Pay (https://www.pnp.co.za/) and Woolworths (https://www.woolworths.co.za/) employ a dietitian and have nutrition education initiatives. In addition, some of these retailers have partnered with medical aid companies to offer cashback when healthier food items are purchased at these retailers' stores (for example, Discovery Ltd. https://www.discovery.co.za/portal/). Whilst the PURE participants viewed practical context-based advice necessary to aid them in the management of CNCDs, the DoH officials considered policies and legislation, community participation and inter-sectoral partnerships as the best options to address the CNCD crisis. It appears that even though the DoH has a holistic approach to address the CNCD epidemic, a gap exists in that their efforts (advice/ health messages) do not seem to be practical enough or acceptable for the target group to implement them.

\section{Limitations}

The following limitations need to be considered. The PURE participants included a small number of male respondents, but adult women have been identified as a group at increased risk of obesity and related CNCDs. The small number of DoH officials interviewed might also have influenced the results. Finally, as this

Table 4. Obstacles to address the CNCD epidemic identified by DoH officials according to issues defined during interviews.

\begin{tabular}{|c|c|c|}
\hline Issue group identified from MCM interviews & Government level obstacles & Community level obstacles \\
\hline Collaboration & $\begin{array}{l}\text { Lack of inter-sectoral collaboration with } \\
\text { governmental departments }\end{array}$ & \\
\hline Commitment & $\begin{array}{l}\text { Not obtaining buy-in from business sector } \\
\text { prior to drafting policy or legislation }\end{array}$ & Community not taking ownership of their health \\
\hline Awareness creation & $\begin{array}{l}\text { Difficulty in finding a balance between } \\
\text { developed countries' investment } \\
\text { (e.g. Kentucky Fried Foods, McDonald's) } \\
\text { and health }\end{array}$ & Easy access to fast food in communities \\
\hline Resources & $\begin{array}{l}\text { Poor recreational resources in living } \\
\text { environments; Poor literacy in majority } \\
\text { of the population }\end{array}$ & $\begin{array}{l}\text { Limited access to recreational facilities in } \\
\text { especially townships } \\
\text { Urbanisation; change in dietary intake, } \\
\text { decreased physical activity due to easy access to } \\
\text { different modes of transport }\end{array}$ \\
\hline Accountability & Poor control of crime & $\begin{array}{l}\text { Crime; unsafe communities for walking } \\
\text { and outdoor activities }\end{array}$ \\
\hline
\end{tabular}


was a cross-sectional study no causal relationship can be inferred.

\section{Recommendations}

The communities which the CNCD programmes are aimed at should be involved from the onset in the development of CNCD interventions. Contextual-based health education should be provided in the language of the communities targeted. The provision of recipes for healthier versions of foods/dishes traditionally consumed should form part of CNCD intervention programmes. This study should be repeated with larger samples and preferably across all provinces of South Africa, in order to provide information for national policy.

\section{Conclusions}

Integration of health service, community participation, food taxation and improving inter-sectoral partnerships were viewed by DoH officials as the most feasible options to address the CNCD epidemic. At community level, the needs for education, shopping lists and healthy recipes were expressed by the PURE participants. Current CNCD interventions should be adapted to include the context-based needs of communities.

Correspondence: Nasheetah Solomons, Department of Dietetics and Nutrition, Faculty of Community Health Sciences, University of the Western Cape, Robert Sobukwe Road/Private Bag X17, Bellville, 7530/7535, South Africa.

Tel.: +27.9592760 - Fax: +27.9593686 .

E-mail: nsolomons@uwc.ac.za

Key words: Chronic non-communicable diseases, intervention programmes, multicriteria mapping.

Contributions: NS was responsible for the research management, conception and design, acquisition, analysis and interpretation of data, drafting the work, revising critically the work for important intellectual content; HSK: analysis and interpretation of data, revising critically the work for important intellectual content; TP: analysis and interpretation of data, revising critically the work for important intellectual content Conflict of interest: the authors declare no potential conflict of interest. Acknowledgements and funding: the authors would like to thank all supporting staff and the participants of the PURE study and in particular: PURE-South Africa: The PURE-WC-SA research team, field workers and office staff in the SoPH, University of the Western Cape, Bellville, South Africa. PURE International: Dr S Yusuf and the PURE project office staff at the Population Health Research Institute (PHRI), Hamilton Health Sciences and McMaster University. ON, Canada. We would also like to thank Department of Health officials who participated in this study. The authors also acknowledge the National Research Foundation of South Africa (NRF) for the financial support. Opinions, findings, conclusions and recommendations expressed in this paper are those of the authors, and the funders accept no liability whatsoever in this regard.

Received for publication: 14 December 2018.

Revision received: 5 August 2019.

Accepted for publication: 3 September 2019.

oCopyright: the Author(s), 2019

Licensee PAGEPress, Italy

Journal of Public Health Research 2019;8:1534

doi:10.4081/jphr.2019.1534

This work is licensed under a Creative Commons Attribution NonCommercial 4.0 License (CC BY-NC 4.0).

\section{References}

1. Dyson P. Addressing noncommunicable disease at population level: a focus on diabetes. Diab Man 2014;4:153-63.

2. Statistics South Africa. Mortality and causes of death in South Africa. Pretoria. Statistics South Africa. 2016. Available from: www.statssa.gov.za/publications/P03093/P030932016.pdf

3. Western Cape Government. Western Cape on Wellness tackles activity levels and healthy eating in Province. 2015. Available from: https://www.westerncape.gov.za/news/western-capewellness-tackles-activity-levels-and-healthy-eating-province.

4. South Africa. Strategic Plan for the Prevention and Control of Non-Communicable Diseases 2013-17. Available from: http://www.hsrc.ac.za/uploads/pageContent/3893/NCDs\%20S TRAT $\% 20$ PLAN\%20\%20CONTENT\%208\%20april\%20proo f.pdf.

5. Hofman K. Non-communicable diseases in South Africa: A challenge to economic development. S Afr Med J 2014;104:647-8.

6. Mayosi BM, Fisher AJ, Lalloo UG, et al. The burden of noncommunicable diseases in South Africa. Lancet 2009;374:93447.

7. South Africa. Foodstuffs, Cosmetics and Disinfectants Act, 1972 (Act 54 of 1972). Regulations relating to the reduction of sodium in certain foodstuffs and related matters. (Notice 214). Government gazette, 36274, 20 March 2013.

8. National Treasury. Budget speech. 20 February 2019. Pretoria. 2019. Available from: http://www.treasury.gov.za/ documents/national\%20budget/2019/speech/speech.pdf .

9. Teo K, Chow CK, Vaz M, et al. The Prospective Urban Rural Epidemiology (PURE) study: Examining the impact of societal influences on chronic noncommunicable diseases in low-, middle-, and high-income countries. Am Heart J 2009;158:1-7.

10. Khan AR, Al-Abdul Lateef ZN, Al Aithan MA, et al. Factors contributing to non-compliance among diabetics attending primary health centers in the Al Hasa district of Saudi Arabia. J Fam Commun Med 2012;19:26-32.

11. Multicriteria mapping. Available from: http://www.multicriteriamapping.org.

12. Kelly S, Martin S, Kuhn I, et al. Barriers and facilitators to the uptake and maintenance of healthy behaviours by people at mid-life: A rapid systematic review. PLOS One 2016;11:e0145074.

13. Moodie R, Stuckler D, Monteiro C, et al. Profits and pandemics: prevention of harmful effects of tobacco, alcohol, and ultra-processed food and drink industries. Lancet 2013;381:670-9.

14. González-Zapata L, Alvarez-Dardet C, Ortiz-Moncada R, et al. Policy options for obesity in Europe: a comparison of public health specialists with other stakeholders. Publ Health Nutr 2008;12:896-908.

15. Holdsworth M, Kameli Y, Delpeuch F. Stakeholder views on policy options for responding to the growing challenge from obesity in France: findings from the PorGrow project. Obes Rev 2007;8:53-61.

16. McDonald J, Davies GP, Jayasuriya R, Harris MF. Collaboration across private and public sector primary health care services: benefits, costs and policy implications. J Interprof Care 2011;25:258-64.

17. Atun R, Jaffar S, Nishtar S, et al. Improving responsiveness of health systems to non-communicable diseases. Lancet 2013;381:690-7.

18. Aikins A, Kushitor M, Koram K, et al. Chronic non-communicable diseases and the challenge of universal health coverage: 
insights from community-based cardiovascular disease research in urban poor communities in Accra, Ghana. BMC Publ Health 2014;14:S3.

19. Mayosi BM, Flisher AJ, Lalloo UG, et al. The burden of noncommunicable diseases in South Africa. Health in South Africa, series 4. Lancet 2009;374:934-47.

20. Rodic R, Krajnovic V, Howell EM, et al. An evaluation of a chronic disease prevention program in the Republika Srpska (RS) of Bosnia and Herzegovina. Int J Integr Care 2008. Available from: http://www.ijic.org/.

21. Wylie-Rosett J. Fat substitutes and health: An advisory from the Nutrition Committee of the American Heart Association. Circulation 2002;105:2800-4.

22. Miraglio AM. Nutrient substitutes and their energy values in fat substitutes and replacers. Am J Clin Nutr 1995;62:117S-9.

23. Sinclair SE, Copper M, Mansfield ED. The influence of menu labelling on calories selected or consumed: A systematic review and meta-analysis. J Acad Nutr Diet 2014;114:1375-88.

24. Ellison B, Lusk JL, Davis D. Looking at the label and beyond: the effects of calorie labels, health consciousness, and demographics on caloric intake in restaurants. Int J Behav Nutr Phys Act 2013;10:21-9.

25. PURE Adult questionnaire. Available from: http://www. coheart.ca/projects/pure//

26. Yusuf S, Teo K, Anand S, et al. Prospective Urban and Rural Epidemiological Study (PURE) protocol: A prospective cohort study to track changing lifestyles, risk factors and chronic disease in Urban and Rural areas of Argentina, Bangladesh, Brazil, Canada, Chile, China, Colombia, India, Iran, Malaysia, Pakistan, Poland, South Africa, Sweden, Tanzania, Turkey, UAE, and Zimbabwe. 2007. Available from: http://www.phri.ca/pure/wp-content/uploads/Protocol_ International_June-01-2015.pdf

27. Stirling A, Coburn J. Multicriteria mapping manual version 1.2. 2015. University of Sussex. Available: https://www.sussex.ac.uk/webteam/gateway/file.php?name=2015-11-swpsmcm-manual-1-2.pdf\&site $=25$

28. Peer N, Lombard C, Steyn K, et al. Differing patterns of overweight and obesity among black men and women in Cape Town: The CRIBSA study. PLOS One 2014;9:e107471.

29. Draper CE, Davidowitz KJ, Goedecke JH. Perceptions relating to body size, weight loss and weight-loss interventions in black South African women: a qualitative study. Publ Health Nutr 2015;19:548-56.

30. South Africa. Department of Health. National guidelines and policies. Available from: https://www.westerncape.gov.za/ your_gov/55/documents/guides/N.

31. Sommer I, Griebler U, Mahlknecht P, et al. Socioeconomic inequalities in non-communicable diseases and their risk factors: an overview of systematic reviews. BMC Publ Health 2015; $15: 914$.

32. Steyn NP, Jaffer N, Nel J. et al. Dietary intake of the urban black population in Cape Town: The Cardiovascular Risk in Black South Africans (CRIBSA) study. Nutrients 2016;8:285.

33. Khandelwal V. Global intervention for prevention and control of non-communicable diseases. Int J Med Sci Publ Health 2013;2:780-4.

34. Gaziano TA, Pagidipati N. Scaling up chronic disease prevention interventions in lower-and middle-income countries. Ann Rev Publ Health 2013;34:317-35.

35. Department of Health. Regulations relating to the reduction of Trans Fats in Food Stuff. Government gazette 2011. Pretoria: Department of Health. Available from: http://www. doh.gov.za/docs/foodcontrol/fortification/ 2011/Regulation\% $20-0$ Fortification $\% \quad 20-20$ Regulations $\% 20$ relating\%20to $\% 20$ transfat $\% 20 \mathrm{in} \%$ 20foodstuffs.pdf.

36. News 24. Sin taxes: Prepare to pay more for cigarettes and booze. 2016. Available from: http://mg.co.za/article/2016-0224-sin-taxes-prepare-to-pay-more-for-cigarettes-and-booze.

37. Department of National Treasury. Policy paper: Taxation of sugar-sweetened beverages. July 2016. Available from: http://www.treasury.gov.za/public\%20comments/Sugar\%20sw eetened\%20beverages/POLICY\%20PAPER\%20AND\%20PR OPOSALS\%20ON\%20THE\%20TAXATION\%20OF\%20SU G A R \% 20 S W E E T EN E D \% 20 B E V E R A G E S 8\%20JULY\%202016.pdf.

38. Colchero MA, Popkin BM, Rivera JA, Ng SW. Beverage purchases from stores in Mexico under the excise tax on sugar sweetened beverages: observational study. BMJ 2016;352:h6704.

39. Department of Health. Regulations relating to the labelling and advertising of foods: Amendment. Pretoria: Department of Health. Notice (429). Government Gazette, 37695. 29 May 2014. Available from: http://www.gpwonline.co.za/ Gazettes/Gazettes/37695_29-5_Health.pdf

40. Miller Soederberg LM, Cassady DL. The effects of nutrition knowledge on food label use. A review of literature. Appetite 2015;92:207-16.

41. Van Deventer C. Integration of non-communicable chronic diseases (NCDs) and HIV/AIDS and mental health care through the involvement of chronically ill patients using empowerment evaluation. S Afr Fam Pract 2015;57:337-46.

42. Puska P. Successful prevention of non-communicable diseases: 25 year experiences with North Karelia Project in Finland. Publ Health Med 2002;4:5-7. 